\title{
ADRENAL FUNCTION AFTER PEDIATRIC CARDIAC SURGERY DETERMINED BY GAS CHROMATOGRAPHY-MASS SPECTROMETRY
}

\author{
H. Steckel ${ }^{1}$, C. Neuhäuser ${ }^{2}$, R.-H. Bödeker ${ }^{3}$, J. Thul ${ }^{4}$, D. Schranz ${ }^{4}$, M. Heckmann ${ }^{1}$ \\ ${ }^{1}$ Dept. of General Pediatrics and Neonatology, Justus Liebig University, Giessen, ${ }^{2}$ Soins Intensifs \\ Pediatriques, Clinique Pediatrique, Centre Hospitalier de Luxembourg, Luxembourg, ${ }^{3}$ Institute of Medical \\ Statistics, ${ }^{4}$ Dept. of Pediatric Cardiology, Justus Liebig University, Giessen, Germany
}

Objective: To address the questions whether cardiac surgery with cardiopulmonary bypass (CPB) triggers a more intense adrenal stress response and an altered cortisol metabolism compared to surgery without CPB?

Methods: Urinary excretion rates of 15 glucocorticoid metabolites (GM) were determined pre- and postoperatively in 29 patients undergoing cardiac surgery with CPB (median age 7.6 months) and 19 patients without CPB (8 months) using gas chromatography-mass spectrometry. GM were summed to calculate cortisol production rates (CPR; $\mathrm{mg}$ mmol creatinine ${ }^{-1} \mathrm{~m}^{-2}$ body surface area). These ratios were calculated to characterize the activity of 11ß-hydroxysteroid dehydrogenase (11ß-HSD):

ratio 1: $(\mathrm{THF}+5 \mathrm{aTHF}) / \mathrm{THE}$ and

ratio 2: $(\mathrm{THF}+5 \mathrm{aTHF}+\alpha-\mathrm{Cl}+\beta-\mathrm{Cl}) /(\mathrm{THE}+\alpha-\mathrm{Cln}+\beta-\mathrm{Cln})$.

The $3^{\text {rd }}$ ratio $(\mathrm{F}+\mathrm{E}) /(\mathrm{THF}+5 \mathrm{aTHF}+\mathrm{THE})$ was calculated to characterize total cortisol metabolism including hepatic ring-A reduction.

Results: Preoperative CPR (median (interquartile-range)) were: CPB: 2.7 (2.1-3.6), controls: 2.4 (1.6-4.2) $(p=0.38)$. Postoperatively, CPR increased $(p<0.001)$ in both groups: CPB: 9.3 (4.5-15.1), controls: 5.1 (1.98.7) with a trend to a higher increase in CPB ( $\mathrm{p}=0.0877)$. Postoperatively, ratio 1 and 2 increased without a difference between groups: pre-/postoperatively: ratio 1: CPB: $0.94(0.62-1.38) / 1.22(0.96-2.62)$ controls: 0.9(0.4-1.09)/1.33(0.98-1.85); ratio 2: CPB: $0.71(0.51-1.09) / 1.02(0.76-2.00)$ controls $0.90(0.44-1.09) / 1.33$ $(0.98-1.85) ; \mathrm{p}<0.0001)$. $\mathrm{CPB}$ influenced the $3^{\text {rd }}$ ratio: preoperative: $0.07(0.06-0.09)$, postoperative 0.14(0.09-019); $\mathrm{p}=0.0017)$.

Conclusions: Surgery resulted in an increase by 2 fold in median CPR in controls and by more than 3 fold in children undergoing surgery with CPB. The postoperative increase of CPR was accompanied by reduction of cortisol inactivation in both groups whereas the postoperative total cortisol metabolism including hepatic ring-A reduction was effected by $\mathrm{CPB}$ only. 